\title{
Application of Artificial Intelligence in College Dance Teaching and Its Performance Analysis
}

\author{
https://doi.org/10.3991/ijet.v15i16.15939 \\ Yingping Wang $\left({ }^{凶}\right)$ \\ Jimei University, Xiamen, China \\ kionwangesina.com \\ Guang Zheng \\ Huaqiao University, Xiamen, China
}

\begin{abstract}
Artificial intelligence (AI) has not been widely and deeply implemented in dance teaching of colleges. To solve the problem, this paper identifies the problems with the $\mathrm{AI}$ in college education and dance teaching, theoretically discusses the application strategies of the AI in dance teaching of colleges, and demonstrates the promotive effect of $\mathrm{AI}$ in college dance teaching. Next, a performance analysis model was established based on fuzzy interval number, grey system theory, and analytic hierarchy process (AHP), and adopted to evaluate the performance of the AI application in college dance teaching. The research results shed a new light on the application of cutting-edge techniques in college education.
\end{abstract}

Keywords-Dance teaching, colleges, artificial intelligence (AI), performance analysis, analytic hierarchy process (AHP).

\section{Introduction}

The rapid development of science and technology makes AI to be widely used in more and more engineering fields, providing a very strong support for the improvement of the design capability and design competitiveness of complex system engineering projects [1-2]. With the continuous expansion of the application scope of AI, AI is playing an increasingly important role in higher education and has received great attention from higher education researchers, and it becomes a hot topic in the research of intelligent higher education [3-4]. Dance teaching is an important part of higher education, the transfer of knowledge related to dance skills, dance moves, and dance expression requires to pay more attention to the teaching details, which makes the AI have a very broad application prospect in dance teaching. To this end, how to effectively apply AI to higher education and dance teaching in colleges and universities is of great urgency. Many researchers have launched a series of studies on it, for example, Peng [5] discussed the constraints and strategies for the development of dance teaching in colleges and universities in the context of "Internet+". Luo [6] analyzed how to apply modern education technologies in dance teaching in colleges and 
universities. Ahmad and Ghapar [7] others discussed the impact and challenge brought by AI to the higher education in Malaysia. Zeng et al. [8] analyzed the impact of the new technological revolution on higher education. Shen [9] discussed the impact of new media development on dance teaching in colleges and universities and its value. Dai and $\mathrm{Wu}[10]$ have studied how to improve the dance teaching ability of colleges in the new media era.

Currently, the application of AI in dance teaching in colleges and universities is not deep enough. With the continuous development of AI, when applying many emerging intelligent technologies in dance teaching, new operational problems will appear inevitably, which would make the existing research generate the problem of insufficient adaptability; moreover, since researchers have very different starting points, it has laid certain limitations to the application strategies and development prospect of $\mathrm{AI}$ in dance teaching. To this end, by referring to existing research results, this paper theoretically analyzes the application strategies of AI in dance teaching in colleges, by comprehensively using fuzzy interval numbers [11-13], gray system theory [14-15] and AHP method, it constructs a corresponding performance analysis model. The content of this paper includes 6 parts. The first part gives an overall introduction to the related research concerning the application of AI in dance teaching; the second part analyzes the problems existing in the AI application in dance teaching; the third part discusses the supportive role of $\mathrm{AI}$ in the dance teaching of colleges; the fourth part analyzes the application strategies of $\mathrm{AI}$ in modern dance teaching; the fifth part realizes the performance analysis of AI in dance teaching; and the sixth part gives the conclusion of this paper.

\section{Problems in Dance Teaching Based on AI Application}

\subsection{Simple content of dance teaching}

At present, in terms of the application of AI in the dance majors, colleges and universities generally choose some representative dance works for teaching, while ignoring the various and diversified basic dance knowledge and dance resources, especially under the condition of the constantly developing AI technology, the teaching content is still the traditional dance works, which cannot catch up with the trend of the times, and cannot highlight the contemporary nature of the dance content, so there's a disconnection between the teaching content and the times.

\subsection{Lagging dance teaching methods}

At present, the dance teaching in colleges still uses the traditional teaching method, that is, dance teachers explain and analyze the dance knowledge, dance moves and related skills in the class; for complex knowledge points or movement tips, it still requires the explanation and demonstration of dance teachers, and then the dance major students are required to practice repeatedly to learn, train and consolidate the dance knowledge. This kind of teaching method would bring poor experience and 
cognition feelings for students, and cannot mobilize students' learning initiative, thereby affecting their interests in learning.

\subsection{Unclear dance teaching goal}

Traditional dance teaching generally focuses on the beauty and appeal of dance movements. Therefore, in the dance teaching process, the key knowledge points that the dance teacher imparts to the students often emphasize on how to complete highquality dance movements, and the training and development of dance skills. However, due to the rapid development of AI technology, people's understanding of dance has undergone fundamental changes. Besides the beauty and appeal of dance movements, people are paying more attention to the cultural content and spiritual expression of the dance performances, especially the expression forms of the fusion of people's spiritual world and the traditional culture in the intelligent society. It can be seen that, the current goal of dance teaching in colleges and universities should give more consideration to the impact of AI on dance teaching, and it should be able to reflect the essence of $\mathrm{AI}$ in the dance world.

\subsection{Insufficient investment in dance teaching}

At present, although colleges and universities are implementing quality education to let students develop in an all-round way in terms of virtue, intelligence, physical fitness, beauty and labor. However, considering the different educational levels of different disciplines or majors and the requirements on science and technologymajored talents, compared with the investment in other science and engineering majors, the investment in dance major is relatively weak, and this has resulted in that the dance major has deficiencies in the introduction of intelligent equipment or advanced technologies in terms of discipline construction, thereby making the discipline construction of dance major cannot satisfy the hardware facility requirements of dance teaching in the era of AI.

\subsection{Insufficient AI application}

Although AI has a wide range of applications in many engineering fields, its application and promotion in higher education still has certain limitations due to the restriction of higher education resources, especially among the disadvantaged disciplines of higher education, the application of AI in art majors has many difficulties, for example, the hardware and software for the AI-based dance teaching is lacking, the technical support ability and methods for the application of AI in dance teaching is limited, and the faculty competence for the AI-based dance teaching is very weak, making the teaching concept of the AI-based dance teaching in colleges and universities not deep enough. 


\section{The Supporting Role of AI in Dance Teaching}

\subsection{Richer dance teaching methods}

The application of AI makes the dance teaching methods becomes much richer, for example, under the support of AI, by installing sensors in key human parts such as face, head, neck, elbows, body torso, buttocks, hips, legs, etc., we can collect human body data of students when they are performing dance movements in real time, capture their facial expressions and dancing gestures, thereby achieving difference analysis on their dance expressions and gestures. Moreover, we can also use AI to obtain various data such as the dance teachers' dance skills, movements, and motions etc., then convert it into digitals and construct a three-dimensional model library that matches the content of dance teaching, display the three or more dimensional content of dance teaching in real time, and form a digital-form dance teaching method.

\subsection{Stronger ability of dance teaching platform construction}

The application of AI in dance teaching integrates flipped classroom, rain classroom, and MOOC into dance teaching. On the one hand, the implementation of the new-type dance teaching modes can provide a better dance teaching support platform for dance teachers, the dance teachers can display the key points, difficult points and key knowledge points of dance teaching from multiple angles, perspectives, and modes, and improve the quality and efficiency of dance teaching; on the other hand, it could provide dance major students with various autonomous learning forms and communication platforms, so that the dance major students can combine with their own personal situations to make rational arrangements to the professional course learning time and content, better stimulate the learning enthusiasm and passion in the dance major students, and achieve better learning effect of students. Moreover, the implementation of the new-type dance teaching modes can make the learning communication among students smoother, and the problems and shortcomings existing in the dance teaching and learning process could be discovered more timely and comprehensively, thereby improving the weak links in dance teaching and learning in a more targeted manner, developing new and targeted dance teaching and learning methods and the related countermeasures, thereby constructing a more complete teaching platform.

\subsection{Higher adaptability of the mixed dance teaching mode}

With the progress of the application of AI in dance teaching, the teaching mode technically supported by Internet+ and combines online and offline multi-channel interaction can better adapt to the requirements of the modern dance teaching. In this mixed dance teaching mode, on the one hand, offline courses are mainly focused on the training of professional dance skills and key movements; on the other hand, the online courses are mainly focused on the basic dance knowledge, the training of dance 
movements, and the timely answering of students' questions, thereby forming a learning environment and atmosphere for the students' online communication and learning.

\subsection{Better dance teaching curriculum planning}

Due to the application of AI, the overall planning of the dance courses can be decomposed into multiple scattered course modules or course knowledge points, moreover, during the implementation process of dance teaching, we can combine with the specific implementation situation of the dance courses to adjust, improve and optimize the dance teaching; also, by examining the self-learning status of dance students, adaptive changes could be made to aspects such as course content, course lecturing sequence, and course evaluation method, etc., so that the dance students' interest and enthusiasm could be improved in a more targeted manner, and students could maintain a stronger desire to explore the dance knowledge, and their autonomous learning ability could be better improved.

\subsection{Highly innovative dance teaching content}

The application of AI technology has not only caused a huge change in the dance teaching mode, but also enriched the learning resources of dance teaching, especially under the joint effect of network technology, information technology and computer technology, colleges have constantly enhanced their ability in network platform construction, which makes the schools highly operable in terms of the compilation and promotion of excellent dance teaching courses, and it has a significant role in enriching, optimizing and innovating the teaching content.

\subsection{More advanced concept of dance education}

With the deepening of AI application in higher education, in the new era, the concept of dance education should be able to reflect the essence and characteristics of the dance teaching in colleges and universities, especially in the practice and thinking of dance teaching in colleges, a scientific cognition for dance education should be formed, including the AI-supported dance education purpose, goals, ideas, missions, and principles, etc. The concept of dance education is a reflection on the present situation of dance teaching in colleges and universities, and it is also a conscious and true reflection of the dance teaching subjects to the reality of dance education. Therefore, in the grand environment of AI application, the concept of dance education should reflect the intelligent nature of dance teaching.

\subsection{Improved dance teaching quality and efficiency}

The application of AI not only enhances the colleges' ability in dance teaching platform construction, provides a solid hardware support to the intelligentization of dance teaching, but also enriches the dance teaching methods and paths, and makes 
the course planning of dance teaching be more in line with the students' cultivation goals under the guidance of the new educational concept. On the one hand, it not only helps the dance teachers to successfully complete the dance teaching tasks and simplify the complex dance teaching process; on the other hand, it is also easier to arouse the students' interest in learning, so that they are willing to invest more energy and ability in the autonomous learning of dance courses; thereby improving the teaching quality and efficiency of dance teaching.

\section{Countermeasures for AI Application in Modern Dance Teaching}

\subsection{Make the hardware equipment of dance teaching more intelligent}

To make the dance teaching more intelligent, the primary condition is to ensure that the hardware equipment used to support dance teaching is of high performance. This is because besides the lecturing of basic dance knowledge, the teaching content involves many aspects, such as dance skills, moves, expression, and performance environment, etc. It needs to clearly capture the techniques and movement tips in dance teaching, provide dance major students with a good dance performance atmosphere so that they could have strong experience and immersion feelings, thereby more effectively providing intelligent supports for dance teaching; if the hardware equipment fails to give such support, then we cannot provide basic guarantees for the implementation of these dance teaching content.

\subsection{Expand the application scope of AI in dance teaching}

Although some colleges and universities have already applied AI technologies such as multimedia technology, VR technology, and information technology in the dance teaching process, most of these applications are mainly focused on the partial links of dance teaching, for instance, some focuses on the classroom teaching of dance courses, some focuses on the skill training of dance teaching, and some focuses on the information exchange of dance teaching, on the whole, the AI application is neither systematic nor integral. In addition, since different higher education schools have different financial, material, or manpower resources, the AI application in the dance teaching of colleges and universities is not sustainable. To this end, the author suggests that the AI application in the dance teaching colleges and universities should be systematic and sustainable, and it should be planned as whole and expanded to various links in the dance teaching.

\subsection{Enhance the faculty competence of intelligent dance teaching}

From the current situation of AI application in dance teaching of colleges and universities, it can be seen that the competence of the faculty for intelligent dance teaching is relatively weak. It includes three aspects: first, the basic investment of colleges 
and universities in dance teaching is weak, especially the financial, technical and hardware investment in intelligent dance teaching, which has resulted in a weak basis for the intelligent dance teaching; second, the professional ability of teachers for the intelligent dance teaching is weak, although some dance teachers are good in dance teaching, they may not be familiar with the AI technologies, which makes them be unable to fully utilize AI for the lecturing of the dance knowledge; third, some dance teachers do not have the teaching idea of applying AI technologies in dance teaching, so they still use the traditional dance teaching concept to teach the dance knowledge supported by the modern technologies, obviously, this cannot keep up with the demands of the times. For this reason, the author believes that it is necessary to enhance the faculty competence of intelligent dance teaching from three aspects: increasing the basic investment in dance teaching, improving the professional ability of dance teachers, and changing the teaching concept of dance teachers.

\subsection{Enhance the AI-based dance teaching assessment ability}

At present, the AI application in the dance teaching process of colleges and universities can be divided into two parts: one part faces the teaching links of dance teachers, the other part faces the learning links of dance students, and the application effect of $\mathrm{AI}$ in the dance teaching process is reflected in both the two kinds of links. However, as a new type of dance teaching mode, the application of $\mathrm{AI}$ in dance teaching is only a preliminary application, which makes the college executive level fail to establish a sound and targeted assessment mechanism for the AI-based dance teaching; in some cases, there's even no targeted assessment method for the dance teaching effect based on AI application, and this has resulted in that, for some dance teachers, there's no difference using or not using $\mathrm{AI}$ in the teaching process, and there's no difference using how much AI in teaching. Moreover, similar problems would appear in the learning process of dance students, which will affect the effect of intelligent dance teaching. For this reason, the author believes that, it is necessary to strengthen the AIbased dance teaching assessment ability from multiple perspectives such as "teaching" and "learning", and formulate a perfect dance teaching assessment mechanism based on the application of AI, so that the weak links in the AI-based dance teaching could be found out more effectively, thereby improving the effect of dance teaching.

\subsection{Well manage and plan the intelligent dance teaching}

With the continuous development of AI and the constant improvement of the level of higher education, the application of AI in higher education will become more extensive, and the application prospect will become even wider; especially for the dance teaching that has very strict requirements on technical movements and skill tips, its demand on the AI-based systematic teaching is even stronger, which has resulted in an urgent need to solve the teaching and management problems generating in the AIbased intelligent dance teaching process. If there isn't a good intelligent dance teaching management system or a good intelligent dance teaching planning system, it will make the teaching and management problems continue to accumulate and cannot be 
solved; on the one hand, this would lead to contradictions during the dance teaching process, and thus affecting the teaching enthusiasm of dance teachers; on the other hand, it would weaken the intelligent effect of AI in dance teaching, and thus making the learning effect of students cannot be effectively improved. Therefore, we should make a good and targeted intelligent dance teaching planning program, comprehensively consider the problems existing in the implementation process of the application of $\mathrm{AI}$ in the dance teaching planning program, and then formulate corresponding management system or regulation for the intelligent dance teaching, and these will be able to provide a strong support for the smooth implementation of dance teaching.

\section{$5 \quad$ Performance of AI Application in Dance Teaching}

\subsection{Research methods for performance analysis}

In the performance analysis of the AI application in college dance teaching, this paper comprehensively uses multiple analysis and research methods, including literature review, questionnaire survey, expert consultation, statistical analysis and model analysis methods, etc.

Literature review method: this method forms systematic research results by collecting, collating and summarizing research content related to the development and application of AI technologies, the dance teaching in colleges and universities, and the combination of AI and dance teaching.

Questionnaire survey method: based on the research situation of dance teaching in colleges and universities at present, this method conducts questionnaire survey and analysis on the application of AI in dance teaching in colleges and universities and its application prospects, and then extracts the influencing factors and key features of AI in dance teaching.

Expert consultation method: this method draws on the guidance of experts to provide assistance for the extraction of influencing factors and key features of AI application in dance teaching, meanwhile, it combines with the suggestions of experts, and proposes corresponding implementation strategies.

Statistical analysis method: this method conducts statistical analysis on the samples obtained from the survey; on the one hand, it helps to extract the influencing factors and key features of AI application in dance teaching, on the other hand, it obtains relevant data of AI application in the dance teaching of colleges and universities.

Model analysis method: this method establishes a performance analysis model for the application of AI in the dance teaching of colleges and universities, and it achieves the quantitative analysis of the application effect.

\subsection{Construction of performance analysis system}

In order to be able to comprehensively analyze the application effect of AI in the dance teaching of colleges and universities, it is necessary to conduct a comprehensive performance analysis on the AI application in dance teaching from the perspec- 
tives of the teachers' teaching and the students' learning. In terms of the teachers' teaching, it is necessary to pay attention to the promotive role of AI in the following aspects of dance teaching: teaching mode CA1, teaching means CA2, teaching method $\mathrm{CA} 3$, teaching content $\mathrm{CA} 4$, teaching task planning $\mathrm{CA} 5$, teaching environment and atmosphere CA6, and teaching quality CA7. In terms of the students' learning: it is necessary to pay attention to the promotive role of $\mathrm{AI}$ in the following aspects of dance learning: students' dance skills CB1, dance movements CB2, dance rhythm $\mathrm{CB} 3$, dance expression CB4, innovation ability CB5, and autonomous learning ability CB6. As a result, a performance analysis system for the application of AI in dance teaching in colleges and universities can be constructed, as shown in Fig 1.

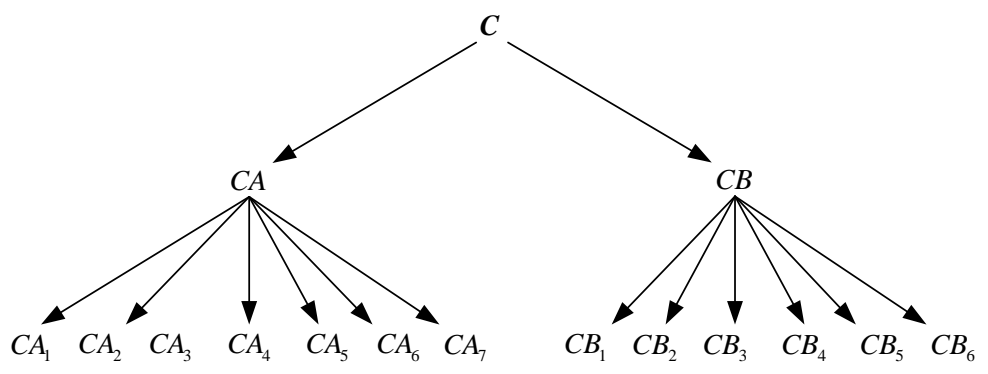

Fig. 1. Performance analysis system

\subsection{Construction of performance analysis model}

Suppose there are a total of $m$ performance analysis objects, wherein the initial data of the $\mathrm{j}$-th performance analysis indicator of the $\mathrm{i}$-th performance analysis object is Vij. If the performance analysis indicator is a performance indicator, the standardized data is Uij:

$$
U_{i j}=V_{i j} / \max _{1 \leq i \leq m}\left(V_{i j}\right)
$$

In particular, if $V_{i j}=\left[v_{i j}^{a}, v_{i j}^{b}\right], v_{i j}^{a} \leq v_{i j}^{b}$, then Uij can be expressed as:

$$
\left\{\begin{array}{l}
U_{i j}=\left[u_{i j}^{a}, u_{i j}^{b}\right], u_{i j}^{a} \leq u_{i j}^{b} \\
u_{i j}^{a}=v_{i j}^{a} / \max _{1 \leq i \leq m}\left(v_{i j}^{b}\right) \\
u_{i j}^{b}=v_{i j}^{b} / \max _{1 \leq i \leq m}\left(v_{i j}^{b}\right)
\end{array}\right.
$$

If the performance analysis indicator is a cost indicator, its standardized data is Uij:

$$
U_{i j}=\min _{1 \leq i \leq m}\left(V_{i j}\right) / V_{i j}
$$


In particular, if $V_{i j}=\left[v_{i j}^{a}, v_{i j}^{b}\right], v_{i j}^{a} \leq v_{i j}^{b}$, then Uij can be expressed as:

$$
\left\{\begin{array}{l}
U_{i j}=\left[u_{i j}^{a}, u_{i j}^{b}\right], u_{i j}^{a} \leq u_{i j}^{b} \\
u_{i j}^{a}=\min _{1 \leq i \leq m}\left(v_{i j}^{a}\right) / v_{i j}^{b} \\
u_{i j}^{b}=\min _{1 \leq i \leq m}\left(v_{i j}^{a}\right) / v_{i j}^{a}
\end{array}\right.
$$

Therefore, the maximum ideal value $U_{j}^{*}$ of the $\mathrm{j}$-th performance analysis indicator can be obtained as:

$$
U_{j}^{*}=\max _{1 \leq i \leq m}\left(U_{i j}\right)=\max _{1 \leq i \leq m}\left(\left[u_{i j}^{a}, u_{i j}^{b}\right]\right)
$$

Then the Euclidean distance [16-18] $D_{i j}^{\Omega}$ between the j-th performance analysis indicator of the i-th performance analysis object and the maximum ideal value $U_{j}^{*}$ can be expressed as:

$$
D_{i j}^{\Omega}=\sqrt{\frac{\left(u_{i j}^{a}-U_{j}^{*}\right)^{2}+\left(u_{i j}^{b}-U_{j}^{*}\right)^{2}}{2}}
$$

If it's analyzed from the perspective of the dance teachers' teaching, then $D_{i j}^{\Omega}$ can be marked as $D_{i j}^{T-\Omega}$; if it's analyzed from the perspective of the dance students' learning, then $D_{i j}^{\Omega}$ can be marked as $D_{i j}^{S-\Omega}$.

Based on the grey correlation analysis theory [19-22], the grey correlation coefficient $\xi \mathrm{ij}$ between the $\mathrm{j}$-th performance analysis indicator of the $\mathrm{i}$-th performance analysis object and the maximum ideal value $U_{j}^{*}$ is:

$$
\xi_{i j}=\frac{\min _{1 \leq i \leq m} \min _{1 \leq j \leq n}\left(D_{i j}^{\Omega}\right)+\rho \max _{1 \leq i \leq m} \max _{1 \leq j \leq n}\left(D_{i j}^{\Omega}\right)}{D_{i j}^{\Omega}+\rho \max _{1 \leq i \leq m} \max _{1 \leq j \leq n}\left(D_{i j}^{\Omega}\right)}
$$

Where, $\mathrm{n}$ is the number of the performance analysis indicators, $\rho$ is the gray correlation identification coefficient, its value generally takes $\rho=0.5$.

Similarly, if it is analyzed from the perspective of dance teachers' teaching, $\xi \mathrm{ij}$ can be marked as $\xi_{i j}^{T}$; if it's analyzed from the perspective of dance students' learning, then $\xi_{\mathrm{ij}}$ can be marked as $\xi_{i j}^{S}$; since different performance analysis perspectives have different weights, and the different performance analysis indicators under the same performance analysis perspective also have different weights, therefore, it's necessary to obtain the weights of the performance analysis indicators. From a simple, accurate, convenient and practical point of view, the weight of each performance analysis indicator can be obtained using the classic AHP method [23-25], that is, assuming that 
under the dance teachers' teaching perspective, the weight of the $j$-th performance analysis indicator is $w_{j}^{T}$, while the weight of the $\mathrm{j}$-th performance analysis indicator under the dance students' learning perspective is $w_{j}^{S}$; then, the weighted gray correlation $\psi \mathrm{i}$ between the i-th performance analysis object with respect to all performance analysis indicators and the maximum ideal value $U_{j}^{*}$ is:

$$
\psi_{i}=w_{T} * \sum_{j=1}^{n_{T}}\left(w_{j}^{T} * \xi_{i j}^{T}\right)+w_{S} * \sum_{j=1}^{n_{S}}\left(w_{j}^{S} * \xi_{i j}^{S}\right)
$$

where, wT represents the weight of the perspective of the dance teachers' teaching, wS represents the weight of the perspective of the dance students' learning, nT represents the number of the performance analysis indicators from the perspective of the dance teachers' teaching, $\mathrm{nS}$ represents the number of the performance analysis indicators from the perspective of the dance students' learning.

By sorting according to the size of the weighted gray correlation $\psi \mathrm{i}$, we can obtain the application effect of $\mathrm{AI}$ in the dance teaching of colleges and universities, thereby achieving the performance analysis of AI application in dance teaching, and providing an effective support to the sustainable development and application of AI in the dance teaching of colleges and universities.

\section{Conclusion}

This paper first analyzed the problems existing in the current process of AI application in the dance teaching of colleges and universities, then it pointed out that the application of AI had played a promotive role in the dance teaching of colleges and universities, and it had an active and promotive effect on many aspects such as teaching concept, teaching platform construction, teaching means, teaching content, teaching mode, and teaching quality. Then, targeting at the problem of how to promote the application ability of AI in college dance teaching, this paper gave multiple application countermeasures from comprehensive perspectives, and evaluated the application effect of AI in dance teaching; moreover, a multi-angle comprehensive performance analysis model was constructed in the paper, which had a very importance significance for promoting the application of $\mathrm{AI}$ in the dance teaching of colleges and universities.

\section{$7 \quad$ References}

[1] Butow, P., Hoque, E. (2020). Using artificial intelligence to analyse and teach communication in healthcare. The Breast, 50: 49-55. https://doi.org/10.1016/j.breast.2020.01.008.

[2] Wan, L., Gong, L.Y., Wu, Q., Mu, D.C. (2018). Application prospect of artificial intelligence in higher medical education. China Medical Education Technology, 32(6): 607-610. https://doi.org/10.13566/j.cnki.cmet.cn61-1317/g4.201806003. 
[3] Lan, G.S., Guo, Q., Zhang, Y., Kong, X.K., Zhong, Q.J (2020). Macro-rends, Technologies \& Practices and Future Affecting the Higher Education Teaching and Learning in Scenarios the Future: Key Points and Considerations of the 2020 EDUCAUSE Horizon Report (Teaching and Learning Edition). Open Education Research, 26(2): 27-39. https://doi.org/10.13966/j.cnki.kfjyyj.2020.02.003.

[4] Hrich, N., Lazaar, M., Khaldi, M. (2019). MAPSS an intelligent architecture for the pedagogical support: Experiment, results \& discussion, International Journal of Emerging Technologies in Learning, 14: 61-79. https://doi.org/10.3991/ijet.v14i21.11012

[5] Peng, J.X. (2018). Constraints and development strategies of college sports dance teaching under the background of "Internet plus". Contemporary Sports Technology, 2018(9): 8081. https://doi.org/ 10.16655/j.cnki.2095-2813.2019.29.080.

[6] Luo, J. (2019). An analysis of the application of modern educational technology in dance teaching in Colleges and Universities. Song of the Yellow River, (16): 75.

[7] Ahmad, M.F., Ghapar, W.R.G.W.A. (2019). The Era of Artificial Intelligence in Malaysian Higher Education: Impact and Challenges in Tangible Mixed-Reality Learning System toward Self Exploration Education (SEE). Procedia Computer Science, 163: 2-10. https://doi.org/10.1016/j.procs.2019.12.079.

[8] Zeng, L.Q., Wang, Y.Y., Zhang, Y. (2019). The New Technological Revolution and Higher Education Reform: Analysis of the Impact of the New Technological Revolution on Higher Education. Journal of Shanghai Polytechnic University, 36(3): 210-215.

[9] Shen, W.R. (2019). Research on the influence and value of new media development on dance education in Colleges and Universities. Science \& Technology Information, 17(6): 114-115. https://doi.org/ 10.16661/j.cnki.1672-3791.2019.06.114.

[10] Dai, X.H., Wu, J. (2019). Research on the promotion of dance teaching in Colleges and universities in the new media era. Sports World, 2019(1): 143-144. https://doi.org/10.16730/j.cnki.61-1019/x8.2019.01.093

[11] Gündoğdu, F.K., Kahraman, C. (2019). A novel fuzzy TOPSIS method using emerging interval-valued spherical fuzzy sets. Engineering Applications of Artificial Intelligence, 85: 307-323. https://doi.org/10.1016/j.engappai.2019.06.003.

[12] Campos, J.R., Assunção, E., Silva, G.N., Lodwick, W.A., Teixeira, M.C.M., MaquiHuamán, G.G. (2020). Fuzzy interval optimal control problem. Fuzzy Sets and Systems, 385: 169-181. https://doi.org/10.1016/j.fss.2019.05.003.

[13] Behera, D., Chakraverty, S. (2020). Solving the nondeterministic static governing equations of structures subjected to various forces under fuzzy and interval uncertainty. International Journal of Approximate Reasoning, 116: 43-61. https://doi.org/10.1016/j.ijar.2019. $\underline{10.011 .}$.

[14] Javed, S.A., Mahmoudi, A., Khan, A.M., Javed, S., Liu, S. (2018). A Critical Review: Shape Optimization of Welded Plate Heat Exchangers based on Grey Correlation Theory. Applied Thermal Engineering, 144: 593-599. https://doi.org/10.1016/j.applthermaleng.20 18.08.086.

[15] Thakur, V., Ramesh, A. (2015). Selection of waste disposal firms using grey theory based multi-criteria decision-making technique. Procedia-Social and Behavioral Sciences, 189: 81-90. https://doi.org/10.1016/j.sbspro.2015.03.202.

[16] Prasad, K.S., Chander, O.S., Reddy, G.P., Gururaj, S. (2017). Artificial Intelligence approach for Classifying Molecular Dataset using Density based technique with appropriate Euclidean Distance measure. Materials Today: Proceedings, 4(8): 8827-8836. https://doi. org/10.1016/j.matpr.2017.07.233

[17] Ghorbel, E., Boonaert, J., Boutteau, R., Lecoeuche, S., Savatier, X. (2018). An extension of kernel learning methods using a modified Log-Euclidean distance for fast and accurate 
skeleton-based Human Action Recognition. Computer Vision and Image Understanding, 175: 32-43. https://doi.org/10.1016/j.cviu.2018.09.004.

[18] Beaver, J.E., Dean, R.M. (2019). Using Euclidean distance in the comparative analysis of taxonomic abundance. Journal of Archaeological Science: Reports, 25: 331-340. https:// doi.org/10.1016/j.jasrep.2019.03.022.

[19] Ghosh, T., Martinsen, K., Dan, P.K. (2019). Development and correlation analysis of nondominated sorting buffalo optimization NSBUF II using Taguchi's design coupled gray relational analysis and ANN. Applied Soft Computing, 85: 105809. https://doi.org/10.1016/j. asoc.2019.105809

[20] Shokri, A., Ghanbari, M., Maleki, F.H., Ramezani, L., Amini, P., Tapak, L. (2019). Relationship of gray values in cone beam computed tomography and bone mineral density obtained by dual energy X-ray absorptiometry. Oral surgery, oral medicine, oral pathology and oral radiology, 128(3): 319-331. https://doi.org/10.1016/j.oooo.2019.04.017.

[21] Moonchai, S., Chutsagulprom, N. (2020). Short-term forecasting of renewable energy consumption: Augmentation of a modified grey model with a Kalman filter. Applied Soft Computing, 87: 105994. https://doi.org/10.1016/j.asoc.2019.105994.

[22] Hubeatir, K.A. (2020). Laser transmission welding of PMMA using IR semiconductor laser complemented by the Taguchi method and grey relational analysis. Materials Today: Proceedings, 20: 466-473. https://doi.org/10.1016/j.matpr.2019.09.167.

[23] Kaganski, S., Majak, J., Karjust, K. (2018). Fuzzy AHP as a tool for prioritization of key performance indicators. Procedia CIRP, 72: 1227-1232. https://doi.org/10.1016/j.procir.20 18.03.097.

[24] Balsara, S., Jain, P.K., Ramesh, A. (2019). An integrated approach using AHP and DEMATEL for evaluating climate change mitigation strategies of the Indian cement manufacturing industry. Environmental pollution, 252: 863-878. https://doi.org/10.1016/j.env pol.2019.05.059.

[25] Nayak, S.C., Tripathy, C. (2018). Deadline sensitive lease scheduling in cloud computing environment using AHP. Journal of King Saud University-Computer and Information Sciences, 30(2): 152-163. https://doi.org/10.1016/j.jksuci.2016.05.003.

\section{Authors}

Yingping Wang, Assistant, College of music, Jimei University, master's degree, graduated from Xiamen University, China. Deputy Secretary General of Fujian ballet Association, executive director of Fujian International Standard Dance Association, member of Youth Committee and theory Committee of Fujian Dancers Association. Research direction: dance teaching theory.

Guang Zheng, received the B.S degree in 2002 from FuJian Teachers University of China. He received the M.S.Eng and Ph.D. degrees from the University of Tokushima in 2006 and 2009 respectively. Currently, he is a lecturer with College of Computer Science and Technology, Huaqiao University, China. His research interests include image processing and pattern recognition, etc.

Article submitted 2020-06-01. Resubmitted 2020-07-18. Final acceptance 2020-07-19. Final version published as submitted by the authors. 